\title{
Craniorachischisis in a Partially Trisomic 11 Fetus in a family with Reproductive Failure and a Reciprocal Translocation, $\mathrm{t}(6 \mathrm{p}+; 11 \mathrm{q}-)^{*}$
}

\begin{abstract}
YVONNE M. WRIGHT, $†$ WILLIAM E. CLARK, $\ddagger$ and W. ROY BREG**
Summary. A familial reciprocal translocation $t(6 p+; 11 q-)$ is presented, unbalanced $(6 \mathrm{p}+)$ in the craniorachischisic propositus and balanced in his phenotypically normal father, associated with relative infertility, multiple spontaneous abortions, and failure to produce normal offspring. The karyotype-phenotype relationship is discussed with reference to other published cases of partial trisomy for the distal portion of the long arm of chromosome 11, and the concept of deletionunmasking is briefly considered. The occurrence of major neural groove closure defects due to a variety of translocations in mice is noted. The gametic segregation of balanced and unbalanced karyotypes is unique to each particular translocation making recurrence risk projections hazardous in the absence of prior experience with the particular translocation. The questions of the relative importance of genetic inheritance, chromosomal abnormalities, and many environmental factors including possible specific teratogens in causing neural groove closure anomalies are still unsettled. The paucity of published chromosome studies in these malformations is noted. We urge that cytogenetic studies with banding techniques be undertaken on these cases and their parents in order to expand basic knowledge of the role of chromosomal errors in their aetiology.
\end{abstract}

Craniorachischisis, which combines anencephaly and total spina bifida with meningomyelocele, is the extreme example of defective neural groove closure. Because of their apparent anatomical and epidemiological similarity and the frequency with which one type may be born to a family which has already had another, defects such as craniorachischisis, anencephaly, spina bifida, meningomyelocele, and hydrocephalus are frequently considered together in attempts to elucidate their causes. Anencephaly is the most common and shows wide variation in incidence geographically and ethnically (Green, 1964), rang-

\footnotetext{
Received 10 August 1973.

* This study was supported in part by Public Health Service research grant HD 00339 from the National Institute of Child Health and Human Development and a grant from the Joseph P. Kennedy, Jr Foundation.

t Department of Pathology, Cytogenetics Division, Hartford Hospital, Hartford, Connecticut 06115, USA.

‡ Department of Pathology, Hartford Hospital, Hartford, Connecticut 06115, USA and Department of Pathology, University of Connecticut Health Center.

** Southbury Training School, Southbury, Connecticut and Departments of Pediatrics and Human Genetics Yale University School of Medicine, New Haven, Connecticut, USA.
}

ing from $0 \cdot 12-0 \cdot 8 / 1000$ live births (France), to $0 \cdot 7-$ $2 \cdot 4 / 1000$ (USA), to $3 \cdot 7-6 \cdot 7 / 1000$ (Ireland). In a study of 184 major neural groove closure anomalies in 153 families in the Netherlands, Polman (1950) found evidence for autosomal recessive inheritance after allowing for bias of ascertainment. Other evidence for autosomal recessive inheritance in some cases has been collected by McKusick (1971), who at the same time calls attention to the evidence for environmental factors. Penrose (1957) found a low familial incidence and low concordance among identical twins. He placed less emphasis on the autosomal recessive hypothesis except for isolated instances and felt that anencephaly might be the result of many influences acting singly or in concert in the individual case: polygenic inheritance, environment (nutrition, infection, etc), and chromosomal translocation. Frezal et al (1964) rejected the translocation hypothesis as lacking support, citing (p. 348) a personal communication from Ruffie without giving the numerical sample base and before the advent of chromosomal banding techniques. In 
contrast to others, he found no seasonal or cyclic trends. Recently, with detailed epidemiological considerations, Renwick (1972) has focused attention on blighted potatoes as possible possessors of a teratogen causing anencephaly, and subsequently, an experimental diet derived from blighted potatoes has produced neural groove closure defects in marmoset monkeys (Poswillo, Sopher, and Mitchell, 1972).

The case reported here involves an inherited partial translocation, balanced in the father and unbalanced in his craniorachischisic son, associated with relative infertility, multiple spontaneous abortions, and failure to produce viable offspring. Few cytogenetic studies of neural groove closure defects have been reported. These have yielded negative or diverse results. Where autosomal recessive inheritance has been inferred solely from a horizontal pedigree pattern (Christakos and Simpson, 1969), a familial cytogenetic defect would be equally plausible. Likewise, where multiple neural groove closure defects are born to an individual but by different mates (Popham, 1906; Horne, 1958), a familial translocation should be considered. The present case shows that very small partial translocations may be involved. A need for cytogenetic studies of anencephalics and their parents is demonstrated.

\section{Case History}

A 30-year-old gravida $\mathrm{V}$, para $\mathrm{O}$, abortus IV white female of Irish extraction was admitted to the Hartford Hospital in November 1971 in her 33rd week of gestation, in active labour. A week earlier, because of polyhydramnios, a flat plate of the abdomen was taken disclosing an anencephalic fetus. The fetal heart beat was $160 / \mathrm{min}$, last recorded two hours before delivery. Amniotic fluid was meconium stained. After 11 hours she delivered a $980 \mathrm{~g}$ ( $2 \mathrm{lb} 3 \mathrm{oz}$ ) stillborn craniorachischisic male (see Fig. 1). In November 1970 she had undergone diagnostic dilatation and curettage and laparoscopy for secondary infertility with negative results. In February 1971 she had been admitted with a two-day history of cramps and vaginal bleeding. The uterus was about 6-week gestation size, and evacuation recovered degenerated avascular placental tissue, typical of blighted ovum. The first trimester of this pregnancy was uneventful with no infections or medications. She has no family history of recurrent spontaneous abortions or of malformations. Her husband was adopted and no information is obtainable concerning his natural parents.

\section{Necropsy Examination}

The necropsy was commenced 14 hours after delivery and a specimen of cardiac blood obtained at that time was promptly inoculated into medium for cytogenetic culture.

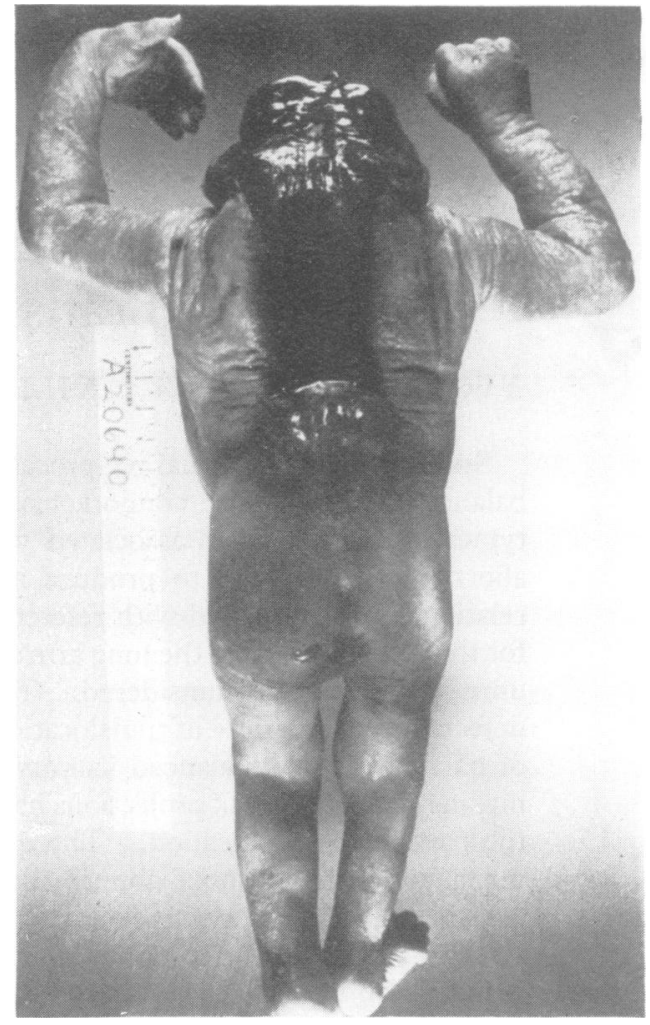

Fig. 1. The propositus.

The body was a typically craniorachischisic male (Fig. 1). There was no maceration. The thoracoabdominal organs and genitalia showed no gross anomalies. The adrenals were somewhat reduced 0 in size due mainly to reduction in the provisional $\dot{0}$ fetal cortex. The microscopic appearance of other viscera was normal. The testes were not sectioned. The pituitary was hypoplastic and devoid of eosinophils. The leptomeninges showed scattered pete- 은 chiae and haemosiderin granules. There was no calcification, necrosis, or inflammatory reaction of the CNS tissues.

\section{Cytogenetic Studies}

Leucocytes were cultured by a standard pro- N cedure using phytohaemagglutinin. The cells were harvested on the third day and stained with 0 Giemsa (without pretreatment to produce banding $\frac{0}{\Phi}$ patterns). The modal number of chromosomes was of 46 (Table I). Ten cells were karyotyped and the 0 only apparent abnormality was a C-group chromo- 0 some with an elongated short arm giving it a meta- 
TABLE I

CHROMOSOME COUNTS

\begin{tabular}{l|c|c|c|c}
\hline & \multicolumn{2}{|c|}{ Chromosome Number } & \multirow{2}{*}{ Total No. of Cells } \\
\cline { 1 - 4 } & $<45$ & 45 & 46 & \\
\hline Propositus & 0 & 2 & 18 & 20 \\
Father & 1 & 0 & 15 & 16 \\
Mother & 0 & 1 & 19 & 20 \\
\hline
\end{tabular}

centric appearance which was indistinguishable from that of a chromosome 3. By quinacrine fluorescence studies (Breg, 1972) the abnormal chromosome was identified as a No. 6 with a small band of chromosomal material added to the short arm, $6 \mathrm{p}+$ (Fig. 2). The other chromosomes appeared normal.

A study of the father's lymphocytes revealed a modal chromosome number of 46 and in Giemsastained metaphase cells a large, metacentric C-group chromosome like that found in the propositus was identified. In addition, a smaller metacentric Cgroup chromosome was found. On further ex- amination with quinacrine fluorescence a $6 \mathrm{p}+$ chromosome and a chromosome 11 with deletion of the distal end of the long arm (11q-) were identified (Fig. 3). Thus, the father is apparently a balanced translocation heterozygote, $t(6 p+; 11 q-)$. The obvious interchange is that of a portion of the long arm of chromosome 11 to the short arm of chromosome 6 (Fig. 4). Presumably a small part of chromosome 6 has been translocated to the long arm of No. 11 ; however, this could not be demonstrated. The mother's chromosomes showed no abnormality.

The fetus, by inheriting the chromosome 6 with a portion of the long arm of No. 11 and a normal chromosome 11 from each parent, is trisomic for part of the long arm of chromosome 11 and also presumably monosomic for the tip of the short arm of chromosome 6 .

\section{Discussion}

Karyotype-Phenotype Relationship. It is uncertain whether the severe maldevelopment of neural groove structures in this case is fortuitous or

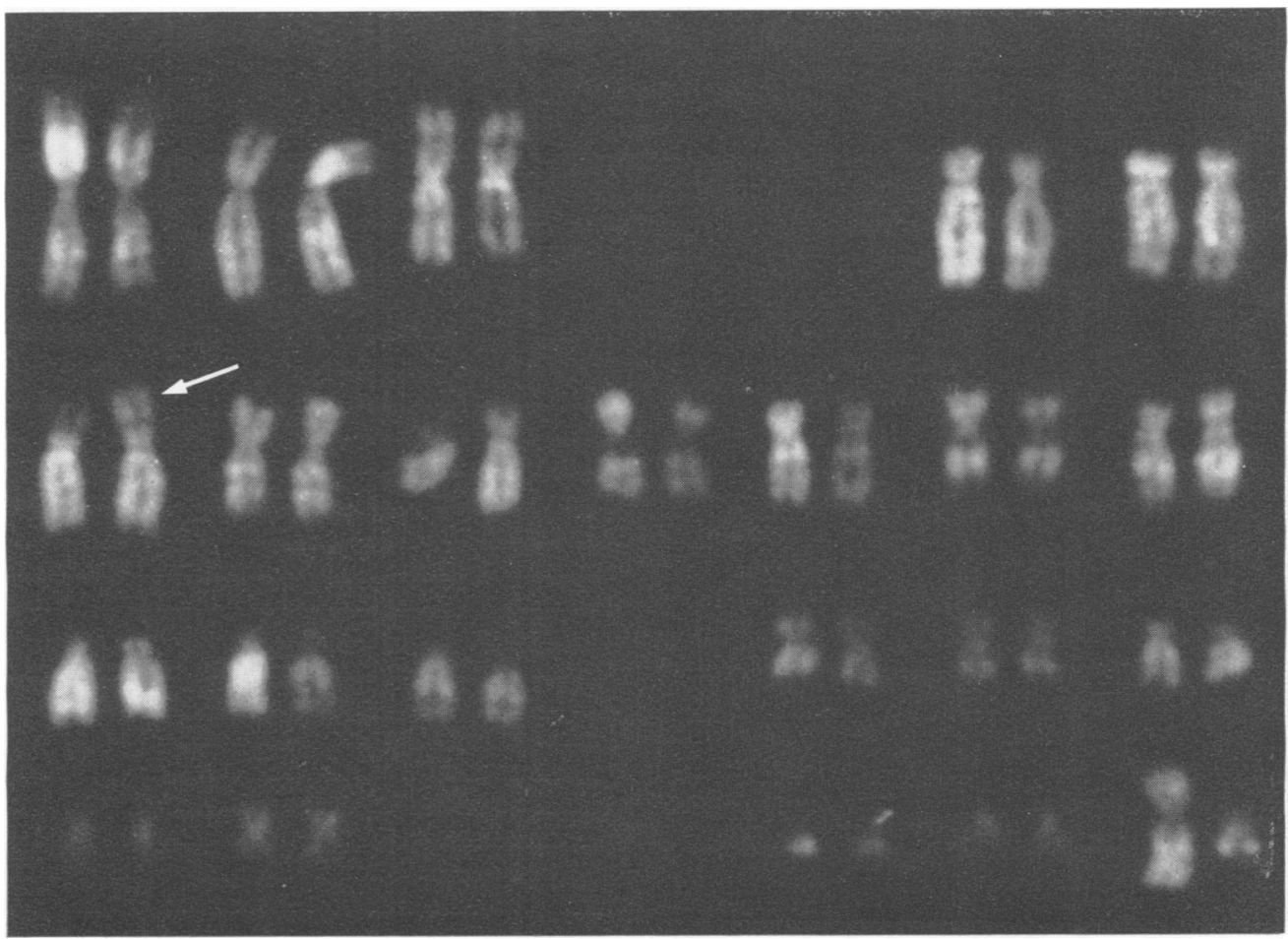

FIG. 2. The unbalanced karyotype of the propositus using the quinacrine fluorescence method; the arrow indicates a chromosome 6 with an elongated short arm $(6 \mathrm{p}+)$. The remaining chromosomes appear normal $(46, \mathrm{XY}, 6 \mathrm{p}+)$. 


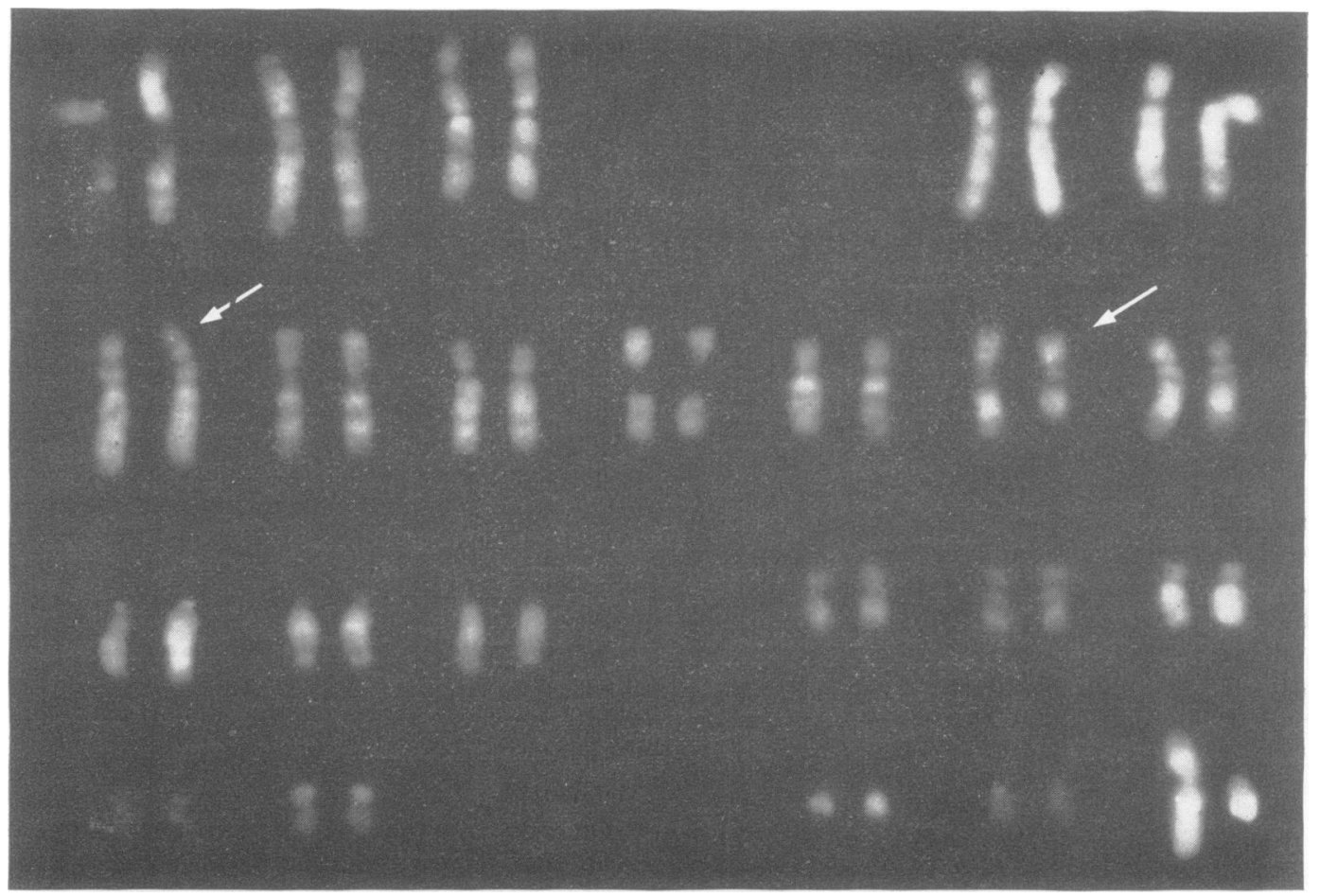

Fig. 3. Karyotype from the father with the $6 p+$ chromosome designated by an arrow on the left and the other arrow pointing to a chromosome 11 with partial deletion of the long arm $(11 \mathrm{q}-)$. He is the carrier of an apparently balanced translocation, $46, \mathrm{XY}, \mathrm{t}(6 \mathrm{p}+$; $11 \mathrm{q}-$ ).

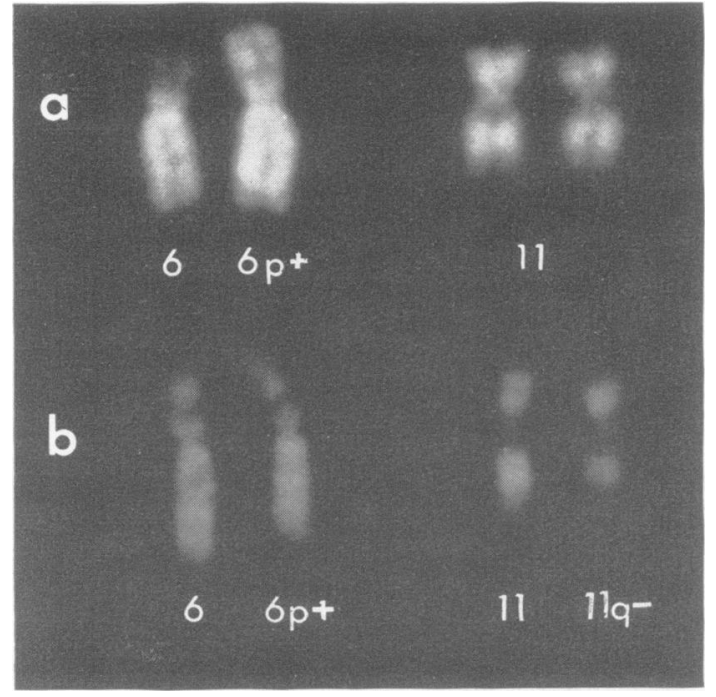

Fig. 4. Partial karyotypes from a propositus and $b$ the father showing the chromosomes $6 \mathrm{p}+$ in both and the $11 \mathrm{q}-$ in the father as well as the normal chromosomes 6 and 11 . is due to the partial trisomy of chromosome 11 or to the postulated terminal deletion (partial monosomy) of chromosome 6 or to both. As with normal persons, malformed individuals occasionally show a 'silent' cytogenetic abnormality unrelated to the malformation. However, in view of the demonstrated familial pattern, balanced reciprocal translocation in the father, chromosomal imbalance of the malformed infant, and the history of consistent reproductive casualty, we favour the malformation and chromosome abnormality not being in chance association.

The disparity of malformations between this case $N$ and case no. 9 of Francke (1972) and the cases of $\sigma$ Rott et al (1972), summarized in Table II, raises N questions to an interpretation based solely on partial N trisomy for the distal portion of the long arm of $\bar{\sigma}$ chromosome No. 11. Postulated partial monosomy 0 of $6 p$ in our case, $4 q$ in Francke's case, and of 13q in Rott's cases due to subterminal breakage is con- of sistent with theory regarding reciprocal transloca- $T$ cation and stable telomeres and may account for phenotypic differences if genetically functional 
TABLE II

ANOMALIES ASSOCIATED WITH PARTIAL TRISOMY FOR THE DISTAL SEGMENT OF THE LONG ARM OF C 11

\begin{tabular}{|c|c|c|c|c|c|}
\hline \multirow{2}{*}{ Anomaly } & \multirow{2}{*}{$\begin{array}{c}\text { Present } \\
\text { Case }\end{array}$} & \multirow{2}{*}{$\begin{array}{c}\text { Francke } \\
1972\end{array}$} & \multicolumn{3}{|c|}{ Rott et al (1972)* } \\
\hline & & & $\mathbf{a}$ & $\mathbf{b}$ & c \\
\hline $\begin{array}{l}\text { Anencephaly } \\
\text { Spina bifida: } \\
\text { meningomyelocele } \\
\text { Agenesis of corpus } \\
\text { callosum } \\
\text { Cranial deformation } \\
\text { Congenital heart disease } \\
\text { Agenesis of one kidney } \\
\text { and one fallopian tube } \\
\text { Biliary system defect } \\
\text { Miscellaneous skeletal } \\
\text { defects } \\
\text { Micrognathia } \\
\text { Cleft palate } \\
\text { Dislocated hips } \\
\text { Clavicles } \\
\text { Clubfoot } \\
\text { Arachnodactyly }\end{array}$ & $\begin{array}{l}+ \\
\mathbf{O} \\
\mathrm{O} \\
\mathrm{O} \\
\mathrm{O}\end{array}$ & $\begin{array}{l}0 \\
+ \\
+ \\
+ \\
+ \\
+ \\
+\end{array}$ & $\begin{array}{l}\mathrm{O} \\
+ \\
+ \\
\mathrm{O} \\
\mathrm{O} \\
\mathrm{O} \\
\mathrm{O} \\
+\end{array}$ & $\begin{array}{l}0 \\
0 \\
+ \\
+ \\
\text { O } \\
\text { O } \\
\text { O }\end{array}$ & $\begin{array}{l}+ \\
0 \\
+ \\
+ \\
+ \\
+ \\
+\end{array}$ \\
\hline
\end{tabular}

* $a$ and $b=$ affected propostus and his affected sister; $c=$ anomalies in one sib and four other relatives of propositus, not karyotyped.

material has been lost. However, such breakage and truly reciprocal exchange apparently involves a segment too small to be distinguished even with the fluorescent technique. The absence of direct evidence for truly reciprocal translocation among Francke's cases led her to question current theory regarding this and telomere stability.

The short subterminal deletion of chromosome 6, if it exists, affords another possible explanation, that of deletion-unmasking of a recessive gene. If the mother of our case were heterozygous for a recessive gene located on the terminal portion of the short arm of chromosome 6 this could be expressed in the conceptus in the absence of an homologous normal gene. Likewise, genetically impaired metabolism of a teratogen could result, although a remarkably frequent or constant exposure would have to be postulated if a teratogen is related to the extent of reproductive casualty in this mating.

Cytogenetic Studies in Neural Groove Closure Defects. Cytological and cytogenetic studies have shown that, with a few exceptions, phenotypic and genetic sex are concordant in anencephaly, and hence, the preponderance of females is not an artefact of gonadal dysgenesis (Benirschke, 1966; Arias-Bernal and Jones, 1967; Arias-Bernal, Vorbeck, and Jacobson, 1967).

Neural tube closure anomalies have been among the findings in several reports of $\mathrm{C}$ trisomy (Warkany et al, 1962; Longo and Maccani, 1965; Riccardi, Atkins, and Holmes, 1970; Caspersson et al, 1972). Longo and Maccani felt that trisomy C-8 was re- sponsible for all six of their cases, although chromosome banding techniques were not available at that time.

Of 40 triploid embryos Carr (1971) cites six with isolated neural tube closure defects although anencephaly was not observed.

In a review of all births for 1962 and 1963 in Cork, Spellman (1966) ascertained seven families with repeated neural groove closure anomalies, of whom six sets of parents were available for cytogenetic study. In one of these, the father had what was interpreted as a balanced non-homologous partial translocation $t(D p+; D p-)$. Although several maternal relatives of this man also had the same D-group pattern, a maternal aunt showed the unbalanced deletion with a normal phenotype, and the involved chromosomal region is of doubtful genetic activity. The author noted the paucity of cytogenetic studies reported on anencephalics and called for further studies. Harnden, Briggs, and Stewart (1959) reported normal karyotypes in two male and two female anencephalic fetuses. However, these authors cautioned that a chromosomal imbalance such as a small translocation might be missed by the techniques then available. D. G. Harnden (personal communication) and Arias-Bernal et al (1967) tabulate a total of 23 anencephalics with no chromosomal abnormality by conventional techniques; likewise, H. Zelleweger, G. Abbo, K. Nielsen, and K. Wallwork (personal communication) found no chromosomal abnormality amongst 15 assorted spinal anomalies.

De Grouchy et al (1964) reported reciprocal translocation between the long arms of two D-group chromosomes, $\mathrm{t}(\mathrm{Dq}+; \mathrm{Dq}-)$, in the father of three infants with neural tube closure defects (2 anencephalic; 1 spina bifida). The infants had died and the presumed association could not be tested.

Animal Studies. The first recognition of chromosomal translocation as a cause of anterior neural groove closure defects was made in 1934 by Snell, Bodemann, and Hollander working with irradiated mice. The inference that a translocation rather than dominant or recessive gene mutation was responsible was based on progeny ratios with various crosses and by analogy with observed chromosomal translocations reported in Drosophilia. When outcrossed with normal, non-irradiated stock, heterozygotes produced the entire gamut: affected progeny, heterozygotes, and normal progeny. Heterozygotes were identified by 'semi-sterility' as it was shown that $42 \%$ of their conceptuses by such crosses were genetically non-viable even though the normal number of zygotes was conceived per mating. 
On sacrificing the pregnant mice at 10-13 days these genetically non-viable conceptuses were found to consist of implantation moles, already dead embryos, and others with distention or clefting of the CNS. In pregnancies coming to term all of the latter were stillborn. The number of viable mice per litter was less than $60 \%$ the normal number for this strain.

In their next report in 1935, Snell and Picken described a second mouse pedigree marked by a similar developmental anomaly but only $4 \frac{1}{2} \%$ reproductive casualty, and observed that several translocations in mice under study at that time gave rise to a similar developmental anomaly; namely, failure of anterior neural groove closure with herniation of the brain. That such pedigrees were indeed the result of induced stable reciprocal translocations was subsequently confirmed by both genetic linkage studies and cytological preparations of meiotic figures (Gruneberg, 1952). Only recently, with the application of chromosome banding techniques, has the tiny reciprocal translocation involved in Snell's original pedigree been demonstrated in mitotic metaphase (Miller et al, 1972).

Recurrence Risk. Several factors in this case combine to render estimation of recurrence risk tenuous.

In a study of the meiotic segregation of reciprocal translocations Ford and Clegg (1969) present 10 possible combinations, only two of which are balanced. Both they and Jacobs et al (1970/1971) emphasize that the relative frequencies of the different types of gametes are probably unique to the particular translocation. Both studies show only a modest increase in spontaneous abortions and stillbirths from matings involving a reciprocal translocation heterozygote. However, of 13 abortions born to heterozygote females in Jacobs' study, five were from one female. In families ascertained through an unbalanced propositus female carriers produced about $15 \%$ unbalanced progeny and male carriers produced about half that frequency. The disparate frequency of affliction in the two translocation strains of mice studied by Snell et al (1934) and Snell and Picken (1935) is further illustration of the unique meiotic segregation behaviour of different translocations. In the absence of accumulated experience with $t(6 p+; 11 q-)$ it would not be sound to apply generalities drawn from other translocations. In this regard it is unfortunate that the karyotypes of our proband's many spontaneously aborted sibs are not known and that the father's parents and other kindred are not available for study.
We wish to thank M. Kirk and E. Hodge for technical assistance.

\section{REFERENCES}

Arias-Bernal, L. and Jones, H. W., Jr. (1967). An anencephalic male with XX sex chromosome complement. American fournal of Obstetrics and Gynecology, 99, 877-878.

Arias-Bernal, L., Vorbeck, R., and Jacobson, C. B. (1967). Cytogenetic anomalies in anencephaly. American Society of Human Genetics Abstracts, 56, 51-52.

Benirschke, K. (1966). Sex chromatin and developmental abnormalities. In The Sex Chromatin, ed. by K. L. Moore, pp. 444452. W. B. Saunders, Philadelphia.

Breg, W. R. (1972). Quinacrine fluorescence for identifying metaphase chromosomes, with special reference to photomicrography. Stain Technology, 47, 87-93.

Carr, D. H. (1971). Chromosomes and abortion. In Advances in Human Genetics, vol. 2, ed. by $\mathrm{H}$. Harris and K. Hirschhorn, p. 223. Plenum Press, New York.

Caspersson, T., Lindsten, J., Zech, L., Buckton, K. E., and Price, W. H. (1972). Four patients with trisomy 8 identified by the fluorescence and Giemsa banding techniques. Fournal of Medical Genetics, 9, 1-7.

Christakos, A. C. and Simpson, J. L. (1969). Anencephaly in three siblings. Obstetrics and Gynecology, 33, 267-270.

De Grouchy, J., Brissaud, H. E., Represse, G., and Lamy, M. (1964). Anencéphalie familiale et remaniement de deux chromosome 1315. Comptes Rendus Hebdomadaires des Seances de l'Academie des Sciences, 259, 691-694.

Ford, C. E. and Clegg, H. M. (1969). Reciprocal translocations. British Medical Bulletin, 25, 110-114.

Frezal, J., Kelley, J., Guillemot, M. L., and Lamy, M. (1964). Anencephaly in France. American fournal of Human Genetics, 16, 336-350.

Francke, U. (1972). Quinacrine mustard fluorescence of human chromosomes: characterization of unusual translocations. American fournal of Human Genetics, 24, 189-213.

Green, C. R. (1964). The frequency of maldevelopment in man. American fournal of Obstetrics and Gynecology, 90, 994-1013.

Gruneberg, H. (1952). The Genetics of the Mouse, p. 503. Martinus Nijhoff, The Hague.

Harnden, D. G., Briggs, J. H., and Stewart, J. S. S. (1959). Nuclear chromatin of anencephalic foetuses. The Lancet, 2, 126-127.

Horne, H. W., Jr. (1958). Anencephaly in four consecutive pregnancies; report of a case. Fertility and Sterility, 9, 67-68.

Jacobs, P. A., Aitken, J., Franckiewicz, A., Law, P., Newton, M. S., and Smith, P. G. (1970/1971). The inheritance of translocations in man: data from families ascertained through a balanced heterozygote. Annals of Human Genetics, 34, 119-131.

Longo, A. and Maccani, U. (1965). Il corredo cromosomico nell'encefalocele. Aggiornamento Pediatrico, 16, 311-318.

McKusick, V. A. (1971). Mendelian Inheritance in Man, 3rd edition, pp. 317-318. Johns Hopkins Press, Baltimore.

Miller, D. A., Allderdice, P. W., Kouri, R. E., Dev, V. G., Grewal, M. S., Miller, O. J., and Hutton, J. J. (1972). Quinacrine fluorescent chromosome analysis of the Snell translocation in the mouse. Genetics, 71, 633-637.

Penrose, L. S. (1957). Genetics of anencephaly. Fournal of Mental Deficiency Research, 1, 4-15.

Polman, A. (1950). Anencephaly, spina bifida, and hydrocephaly: a contribution to our knowledge of the causal genesis of congenital malformations. Genetica, 25, 29-78.

Popham, R. B. (1906). Two cases of anencephaly. Lancet, 1, 1829 Poswillo, D. E., Sopher, D., and Mitchell, S. (1972). Experimental induction of foetal malformation with 'blighted' potato: a preliminary report. Nature, $239,462-464$.

Renwick, J. H. (1972). Hypothesis: anencephaly and spina bifida are usually preventable by avoidance of a specific but unidentified substance present in certain potato tubers. British fournal of Preventive and Social Medicine, 26, 67-88.

Riccardi, V. M., Atkins, L., and Holmes, L. B. (1970). Absent patellae, mild mental retardation, skeletal and genitourinary anomalies, and $\mathrm{C}$ group autosomal mosaicism. Fournal of Pediatrics, 77, 664-672.

Rott, H.-D., Schwanitz, G., Grosse, K.-P., and Alexandrow, G. (1972). C 11/D 13-translocation in four generations. Humangenetik, 14, 300-305. 
Snell, G. D., Bodemann, E., and Hollander, W. (1934). A translocation in the house mouse and its effect on development. Fournal of Experimental Zoology, 67, 93-104.

Snell, G. D. and Picken, D. I. (1935). Abnormal development in the mouse caused by chromosome unbalance. Fournal of Genetics, 31, 213-235.
Spellman, M. P. (1966). Chromosome investigations of anencephaly and other congenital C.N.S. abnormalities in Cork. Irish fournal of Medical Science, 6, 393-398.

Warkany, J., Rubinstein, J. H., Soukup, S. W., and Curless, M. C.

(1962). Mental retardation, absence of patellae, other malforma tions with chromosomal mosaicism. Fournal of Pediatrics, 61, 803-812. 